\title{
REID Basil A., Myths and realities of Caribbean history
}

\section{Stéphen Rostain}

\section{(2) OpenEdition \\ Journals}

Édition électronique

URL : https://journals.openedition.org/jsa/16747

DOI : 10.4000/jsa. 16747

ISSN : 1957-7842

\section{Éditeur}

Société des américanistes

\section{Édition imprimée}

Date de publication : 15 juin 2019

ISBN : 978-2-902715-11-4

ISSN : 0037-9174

\section{Référence électronique}

Stéphen Rostain, "REID Basil A., Myths and realities of Caribbean history ", Journal de la Société des américanistes [En ligne], 105-1 | 2019, mis en ligne le 15 juin 2019, consulté le 02 septembre 2022 URL : http://journals.openedition.org/jsa/16747 ; DOI : https://doi.org/10.4000/jsa. 16747

Ce document a été généré automatiquement le 2 septembre 2022.

Tous droits réservés 


\title{
REID Basil A., Myths and realities of Caribbean history
}

\author{
Stéphen Rostain
}

\section{RÉFÉRENCE}

REID Basil A., Myths and realities of Caribbean history, University of Alabama Press

(Caribbean archaeology and ethnohistory), Tucaloosa, 2009, 154 p., bibliogr., index, ill.

(en noir et blanc), carte, glossaire.

1 Voilà typiquement le genre d'ouvrage que certains Tartuffe de la science considéreront probablement avec dédain, alors que son objectif et son utilité sont évidents. Il s'adresse très clairement à un large public, sans pour autant être inutile aux étudiants et aux chercheurs qui sauront y trouver du plaisir et de l'usage. Ce livre a toutes les chances de rencontrer un lectorat large et varié.

Basil Read enseigne l'archéologie à l'université des West Indies à Saint-Augustine, à la Trinité-et-Tobago. C'est dire si, durant sa carrière, il a dû entendre un bon nombre de billevesées sur les premiers habitants insulaires et les conquérants européens des premières heures. Sa carrière se caractérise, entre autres, par un réel dynamisme éditorial. Outre ses articles et quelques monographies, il a publié en tant qu'éditeur un très honorable nombre d'ouvrages, dont les plus récents sont Caribbean heritage en 2012, Encyclopedia of Caribbean archaeology en 2014 et The archaeology of Caribbean and circumCaribbean farmers (6000 BC-AD 1500) en 2018.

3 Avant cela, sa monographie Myths and realities of Caribbean history cherchait à revenir sur ces images d'Épinal qui polluent les pensées et les manuels scolaires. Les images, ça amuse quand on est petit, mais les adultes ont passé l'âge. Si l'on se doute bien que Clovis n'explosa jamais à coups de francisque le crâne d'un de ses soldats en s'exclamant «Souviens-toi du vase de Soissons! » ou que Hernan Cortés ne brûla pas vraiment ses navires dans la baie d'Acapulco pour empêcher ses soldats de fuir, on reste quand même 
imprégné d'une foultitude d'authentiques anecdotes historiques fausses et de certitudes imaginaires inébranlables sur un passé fantasmé.

Il ne saurait en être différemment dans le Nouveau Monde, d'autant plus que celui-ci fut baptisé à partir d'une félonne usurpation à la cour d'Espagne et d'une habile imposture à Saint-Dié. Si Christophe Colomb fut bien le premier à révéler à l'Europe l'existence de ce continent, ce ne fut pas son nom qui le baptisa pour la postérité cartographique. Ce fut par un habile tour de passe-passe que cette terre prit le prénom d'un navigateur italien moins intrépide, mais dont l'ouvrage Mundus Novus avait su séduire les lecteurs d'alors, et particulièrement les moines cartographes. Un des défenseurs modernes de la réputation de Christophe Colomb, Jakob Wassermann, écrivait ainsi en 1930: «Par une ironie particulièrement sombre, à la suite d'un malentendu et de basses intrigues menées par des gens vils, le continent ressemble à un vaisseau voguant sous un faux pavillon " (Wassermann 1930). Aussi, même si le navire fait eau de toute part, il ne faut pas renoncer à réhabiliter quelques vérités. L'histoire du Nouveau Monde regorge de partis pris et de conjectures, répétés à l'envie dans les livres, particulièrement dans les précis d'école (Figure 1) ${ }^{1}$. Pour les combattre, il est nécessaire que les chercheurs s'expriment et diffusent leurs connaissances vers le grand public.

Basil Read est de ceux-là, notamment en s'attaquant à onze idées reçues communément partagées sur le passé précolombien et postcolombien des îles de la Caraïbe. Il les désigne lui-même comme des mythes et tente, à la lueur des recherches les plus récentes, de les déconstruire pour révéler une réalité plus tangible. C'est donc une œuvre utile qui est publiée ici, permettant de clarifier chez chacun des idées parfois floues. En effet, nul n'est à l'abri d'énoncer des sornettes. Ces préconçus sont exposés en onze chapitres :

Mythe 1: L'histoire caribéenne commence avec l'arrivée de Christophe Colomb en 1492.

Mythe 2: Les Arawaks et les Caribs étaient les deux principaux groupes de la Caraïbe précoloniale.

Mythe 3 : Christophe Colomb rencontra des Arawaks dans la Caraïbe septentrionale.

Mythe 4: Les autochtones rencontrés par Christophe Colomb dans la Caraïbe septentrionale avaient migré depuis l'Amérique du Sud.

Mythe 5 : Les Arawaks étaient les premiers céramistes et agriculteurs à s'être installés dans la Caraïbe.

Mythe 6 : Les Ciboneys vivaient à l'ouest de Cuba à l'époque du contact espagnol.

Mythe 7 : Les Caribs insulaires étaient cannibales.

Mythe 8 : Tous les Amérindiens migrèrent de l'Amérique du Sud vers la Caraïbe, d'île en île depuis le continent jusqu'aux Petites et Grandes Antilles.

Mythe 9: Les Espagnols introduisirent la syphilis dans la Caraïbe et le Nouveau Monde.

Mythe 10: Christophe Colomb écrivit la version de son Diario (Journal) que l'on utilise aujourd'hui.

Mythe 11 : Les colons espagnols apportèrent la « civilisation » aux sociétés autochtones dans la Caraïbe.

6 Ces onze affirmations sont tour à tour évaluées et confrontées aux données historiques et archéologiques pour être finalement mises à mal à l'aune des connaissances actuelles. Cette série d'idées fausses sert en vérité d'habile alibi pour développer de nouvelles hypothèses et, surtout, pour présenter les récentes avancées de l'archéologie de la région. C'est une manière didactique et simple de faire le point des recherches pour le grand public. Le danger, pas toujours évité ici, est évidemment que le développement de la réponse aux «mythes" s'éloigne un peu du sujet principal pour mettre en avant les 
travaux menés par les chercheurs ou pour exposer des thématiques annexes. Cette dérive se ressent parfois dans la conclusion de quelques chapitres, mais c'est un moindre mal face à l'intérêt du contenu général.

7 Certes, de toute évidence, les références à l'île natale de l'auteur abondent, mais cette préférence nationale quelque peu incontournable n'enlève rien au large éventail bibliographique consulté par l'auteur, qui cite des chercheurs d'horizons divers et prend en compte de nombreuses îles de la Caraïbe. Si Basil Reid en appelle à des sources historiques, ethnohistoriques, ethnologiques ou géographiques, il est avant tout un archéologue qui met à l'honneur sa discipline. En attestent les figures choisies, pour l'essentiel ayant trait à l'archéologie: cartes culturelles, fouilles de sites, plans d'excavations et de structures, artefacts, micro-traces d'utilisation, reconstitutions expérimentales, etc.

8 Sans nul doute, c'est produire un acte salutaire que de rectifier de si persistantes et répandues pensées. Dans ce récit actualisé, Christophe Colomb retrouve son noble rang d'Amiral de la mer Océane et redevient l'homme du $\mathrm{Xv}^{\mathrm{e}}$ siècle; la diversité ethnique chère au monde précolombien est remise à l'honneur; les Arawaks et les Caribs qui avaient longtemps cannibalisé les manuels scolaires ont été éliminés au profit des non moins compliqués Saladoïdes, Barrancoïdes, Ostionoïdes, Chicoïdes, Casimiroïdes et autres groupes culturels aux déroutantes dénominations. Si les colons espagnols n'apportèrent pas la « civilisation » dans la Caraïbe, Basil Reid, lui, a apporté un peu de clarté dans son histoire.

Dans sa belle préface du livre, William Keagan, fameux archéologue nord-américain spécialisé dans la Caraïbe, rappelle avec justesse que l'histoire a souvent été « utilisée pour servir des objectifs politiques, culturels et sociaux, à tel point que beaucoup de traités historiques sont plutôt à considérer comme de la propagande " (traduction de l'auteur). Toutes les approximations historiques finissent par faire loi à force d'être rabâchées et les premiers coupables en sont souvent, hélas, les manuels scolaires.

Si l'on fait un survol de cette littérature dans les différents pays d'Amérique du Sud, on ne peut qu'être édifié des incertitudes sur la relation des événements égrenant la conquête européenne. Encore plus inique est la place concédée aux Amérindiens dans l'histoire officielle (voir Rostain 2011). Soit, comme dans certaines publications d'Uruguay, il n'y a jamais eu d'autochtones, soit leur rôle a toujours été mineur. Dans les Andes, on conte rapidement leur résistance à recevoir les bienfaits de la civilisation, ne citant presque exclusivement que les Incas, avant de passer à d'autres épisodes historiques. Dans la suite des manuels scolaires, on élimine tout simplement du cours de l'histoire le nom "Amérindien ", qui disparaît complètement dans les pages consacrées aux époques coloniale et républicaine pour valoriser les faits des colons. Ce génocide littéraire n'est pas sans conséquence sur les mentalités et les attitudes.

11 Par exemple, Laureano Gómez, président ultra-conservateur de la République colombienne entre 1950 et 1953, déclarait en 1928 que : « Notre race provient du mélange des Espagnols, des Indiens et des Noirs. Les deux dernières branches sont des stigmates de complète infériorité. C'est dans ce que nous avons pu hériter de l'esprit espagnol que nous devons chercher les lignes directrices du caractère colombien contemporain " (conférence au théâtre municipal de Santa Fé de Bogotá, 1928). Ce dédain s'accompagnait évidemment d'une négation complète de leurs droits de citoyen, voire des Droits de l'homme tout court. 
12 L'arrogance historique, le révisionnisme politique et l'officialisation d'un racisme ethnique sont donc autant de raisons de soutenir des initiatives de réhabilitation à grande échelle, telle celle mise en œuvre dans cet ouvrage de Basil Reid.

Fig. 1 - Découverte de l'Amérique (dans un manuel scolaire de 1950).

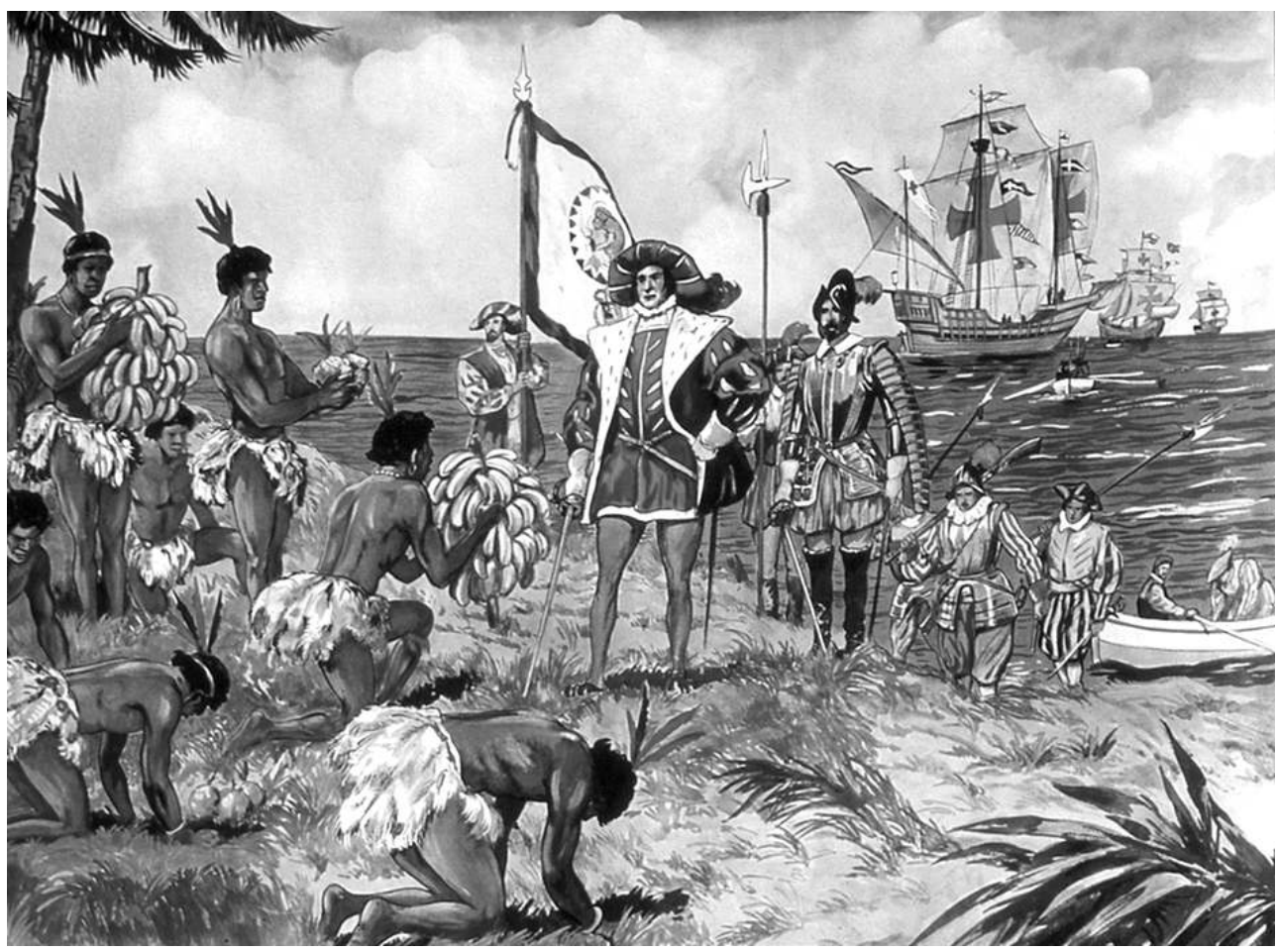

Cette image française du milieu du $x x^{e}$ siècle véhicule à elle seule pléthore d'anachronismes et de morgue. Christophe Colomb et ses hommes sont vêtus à la mode du siècle postérieur, les soldats notamment coiffés du morion, casque emblématique mais en réalité plus tardif. Les Amérindiens, eux, sont noirs aux cheveux crépus, habillés de pagnes en plumes d'autruche et offrant à leurs futurs maîtres des bananes, fruit qui ne fut pourtant introduit qu'au xvi ${ }^{\mathrm{e}}$ siècle en Amérique par les conquistadors.

\section{BIBLIOGRAPHIE}

\section{DUVIOLS Jean-Paul et Michel CHANDEIGNE}

2011 Sur la route de Colomb et Magellan : idées reçues sur les grandes découvertes, Le Cavalier bleu éd. (Idées reçues), Paris.

\section{RosTAIN Stéphen}

2011 «Amazonie : une archéologie en attente de décolonisation », Les Nouvelles de l'archéologie, 126 (dossier " Archéologie(s) en situation coloniale », Alexandra Galitzine-Loumpet, Svetlana Gorshenina et Claude Rapin [dir.]), p. 41-45.

\section{WASSERMANN Jakob}

1930 La vie de Christophe Colomb, Gallimard (Vies des hommes illustres, 55), Paris. 
NOTES

1. À ce sujet, on lira avec intérêt les publications de Jean-Paul Duviols, dont la volonté rectificatrice est comparable à celle de Basil Reid, et plus particulièrement Sur la route de Colomb et Magellan: idées reçues sur les grandes découvertes (en collaboration avec Michel Chandeigne 2011).

\section{AUTEURS}

\section{STÉPHEN ROSTAIN}

Laboratoire « Archéologie des Amériques » (UMR 8096), CNRS 